\title{
Technical problems with compression units in mechanical vapour recompression systems
}

\author{
Władysław Kryłłowicz ${ }^{1}$, Krzysztof Kantyka ${ }^{1, *}$, Włodzimierz Szewczyk ${ }^{2}$, and Paweł Pełczyński ${ }^{2}$ \\ ${ }^{1}$ Institute of Turbomachinery, Lodz University of Technology, Poland \\ ${ }^{2}$ Institute of Papermaking and Printing, Lodz University of Technology, Poland
}

\begin{abstract}
The evidence gathered during works on two prototype heat recovery systems is summarised. The first installation is a low-temperature vapour recompression system, whereas the second is a hightemperature (from an industrial viewpoint) installation. Vapour-contaminated air is the working medium. The authors focused their attention on machine issues mainly. All compressors described below were designed at the Lodz University of Technology.
\end{abstract}

\section{Introduction}

By "mechanical vapour recompression" we understand a special compressor heat pump working in an open loop. A comparison of both systems, a closed system in the case of the classic heat pump and an open one, namely vapour recompression, is shown in Fig. 1.

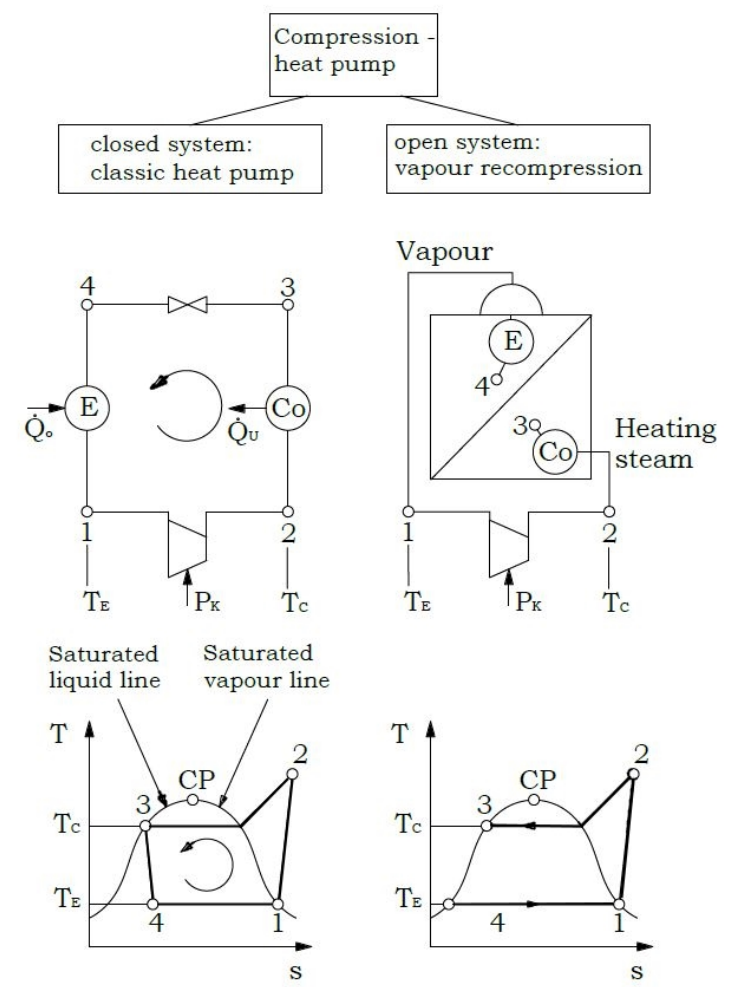

Fig. 1. Comparison of the classic heat pump (left) and the vapour recompression cycle (right)

$\mathrm{E}$ - evaporator, $\mathrm{Co}-$ condenser.

In the closed cycle, a refrigerant (normally used as the working medium) is compressed from state $\mathbf{1}$ to state 2, where $P_{k}$ is the compressor power consumption. Next, the medium is condensed in a heat exchanger (conversion from state $\mathbf{2}$ to state $\mathbf{3}$ ), and the useful heat $\dot{Q}_{u}$ is delivered to the consumer. Then, the working medium is expanded in a throttling valve $\mathbf{3}-\mathbf{4}$ to the pressure corresponding to saturation temperature $T_{E}$. In the last stage of this cycle, the medium is evaporated (4 to 1), due to the fact that the heat $\dot{Q}_{0}$ coming from the waste heat source is delivered to the system. Thus, a compressor heat pump is a device, which converts the low-temperature heat $\dot{Q}_{0}$, through the energy input delivered to the compressor, into useful heat $\dot{Q}_{u}$ at a higher temperature. The vapour recompression operates in the same way, but after compression 1-2 and condensation $\mathbf{2}-\mathbf{3}$ at temperature $T_{C}$, the condensate leaves the cycle. Thus, a throttling valve is not needed.

In fact, in numerous branches of the Polish industry, such as the sugar industry, the food industry or in brewing, vapour recompression installations are met. In the majority of cases, however, they are based not on mechanical compression but on compression in steam-jet ejectors, that is to say, on "thermocompression".

\section{Technical problem in a large vapour recompression installation}

The Ordering Party commissioned a development of the conceptual design, and then a design of a technical vapour compression unit at pressure $p_{A}=1.2$ bar upping the minimal pressure 3.2 bar $+4 \%$ (maximal pressure 3.328 bar). The compression unit was to operate with a rectification column in the way depicted in Fig. 2.

In column 1 (designed for low pressure losses), the input (a mixture of nitrous gases) is separated into fraction $\mathrm{Y}$ at the head and fraction $\mathrm{X}$ at the sump. By means of mechanical energy, the vapours are recompressed by compressor 2 up to the pressure and temperature level necessary for heating the sump

*Corresponding author: krzysztof.kantyka@p.lodz.pl 
evaporator 3. Surplus energy is eliminated in reflux cooler 4.



fraction $\mathrm{X} \quad$ fraction $\mathrm{Y}$

Fig. 2. Rectification column unit with vapour recompression. Point $\boldsymbol{A}$ and $\boldsymbol{Z}$ denote suction and compression of the compression unit, respectively. 1 - column, 2 - compressor, 3 sump evaporator, 4 - reflux cooler.

Water vapour, contaminated with $\mathrm{SO}_{2}, \mathrm{NO}$ and sulphuric acid mist (up to $30 \mathrm{mg} / \mathrm{Nm}^{3}$ ), in the quantity of 15.6 ton per hour $\left(\dot{m}_{\text {vapour }}=4.333 \mathrm{~kg} / \mathrm{s}\right)$, is the working medium.

The required pressure ratio of the compressor is $\Pi=p_{Z} / p_{A}=2.67$. Then, on the assumption that the inner isentropic efficiency of the compressor is at a level of 0.76 , the circumferential velocity of the impeller wheel will exceed $u_{2}=550 \mathrm{~m} / \mathrm{s}$, which is of course impossible to achieve within one compression stage. Thus, the compressor has to have two stages. Taking into account the technological conditions, a scheme of the compression unit, shown in Fig. 3, was developed.



Fig. 3. Scheme of the vapour compression unit: 1 - first compression stage, 2 - second compression stage, 3 - inlet guide vanes, 4 - scrubber-type intercooler, 5 - water mist separator, G - gear box, EM - electric motor.

Fig. 4 depicts a compression curve within the enthalpy - entropy coordinates.

After the initial analysis was completed, it was assumed that the pressure ratio of the first stage of the compressor would be $\Pi_{I}=1.78$, whereas for the second stage it would be $\Pi_{\mathrm{II}}=1.57$. The saturation temperature at the compressor inlet (pressure $1.2 \mathrm{bar}$ ) is equal to $104.81^{\circ} \mathrm{C}(377.96 \mathrm{~K})$. Due to the considerable length of the pipeline, the pressure loss was estimated at $\Delta p=0.01$ bar. Hence, the suction pressure at the first stage is equal to $p_{A_{I}}=1.192 \mathrm{bar}$.

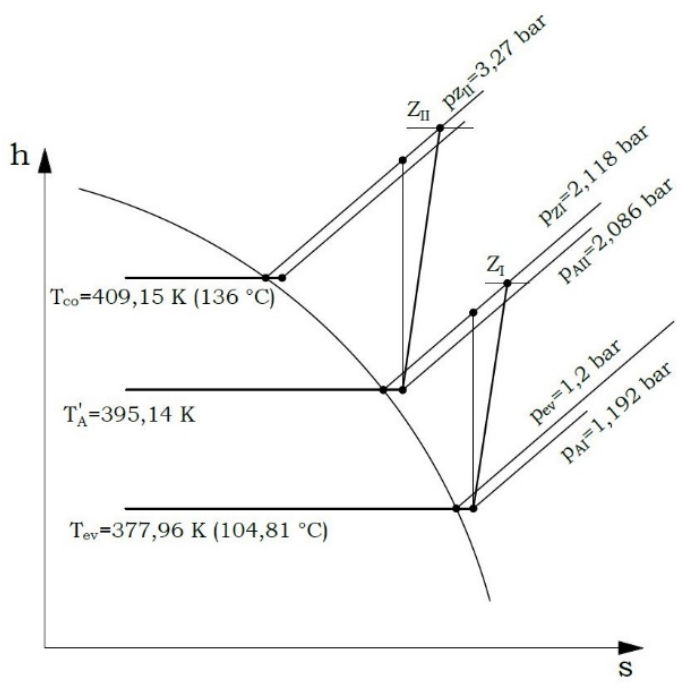

Fig. 4. Compression curve within the $h-s$ coordinates .

It was assumed that the pressure drop in the wet intercooler would be $\Delta p=1.5 \% \cdot p_{Z_{I}}$, that is to say, $0.0318 \mathrm{bar}$, thus the suction pressure in the second stage equals $p_{A_{I I}}=p_{Z_{I}}-\Delta p=2.086 \mathrm{bar}$.

The design assumptions for compression stages were as follows:

1) Semi-open impellers due to strength issues.

2) Welded wheels, consisting of forged hubs and pressed-sheet blades.

3) The first-stage impeller wheel with radial blades, the second-stage impeller wheel with backward-bent blades.

In Table 1, the most important parameters of both stages of the compressor are listed.

Table 1. Basic parameters of the stage.

\begin{tabular}{|l|c|c|c|}
\hline \multicolumn{1}{|c|}{ Stage } & & $\mathbf{1}$ & $\mathbf{2}$ \\
\hline outer wheel diam. $D_{2}$ & $\mathrm{~mm}$ & 496 & 400 \\
\hline outlet blade angle $\beta_{2}^{*}$ & $\circ$ & 90 & 63 \\
\hline circumferential velocity $u_{2}$ & $\mathrm{~m} / \mathrm{s}$ & 403 & 388 \\
\hline rotational speed $n$ & $\mathrm{rpm}$ & 15532 & 18527 \\
\hline isentropic efficiency & $\%$ & 75.5 & 76.0 \\
\hline power consumption & $\mathrm{kW}$ & 684.2 & 545.6 \\
\hline
\end{tabular}

In Fig. 5, a longitudinal section of the first compression stage is presented.

Inlet guide vanes were installed upstream of the impeller inlet for control. Both the first and second stages have vaned diffusers. 


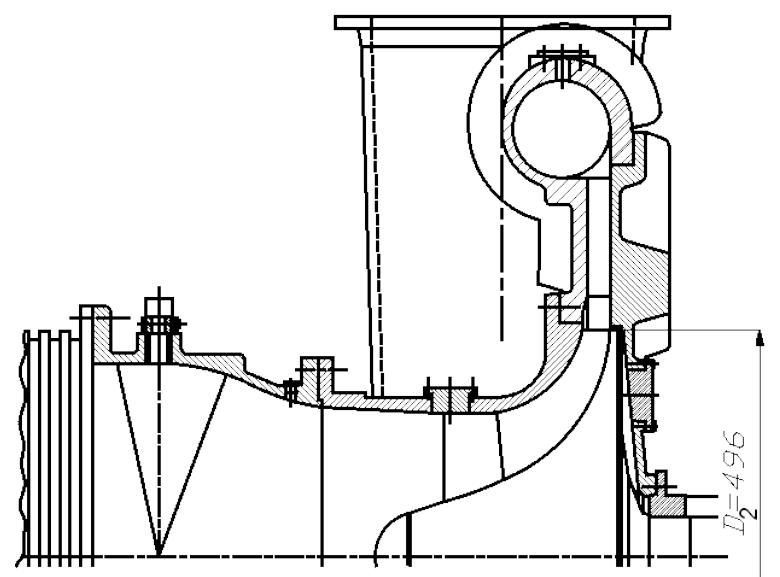

Fig. 5. Longitudinal section of the first compression stage.

The efficiency of heat pumps, including vapour recompression systems, is often characterised by means of the so-called "coefficient of performance" (COP). This is defined as a ratio of the useful heat stream $\dot{Q}_{u}$ and the compressor power $P_{k}$ :

$$
C O P=\frac{Q_{u}}{P_{k}}
$$

In our case:

$$
C O P=\frac{r \cdot \dot{m}}{P_{e l_{1}}+P_{e l_{2}}}=\frac{2154.2 \cdot 4.333}{684.2+545.6}=7.59
$$

where $r$ denotes evaporation heat at temperature $T_{c}$.

Thus, the vapour recompression system under study is very beneficial from the energy generation point of view.

\section{Design of a high-temperature compressor system}

The Ordering Party formulated the following requirements referring to the blower parameters:

- suction pressure: $\quad p_{A}=1.01325$ bar

- suction temperature: $\quad T_{A}=673 \mathrm{~K}\left(400^{\circ} \mathrm{C}\right)$

- suction volume flow rate: $\dot{V}_{A}=1 \mathrm{~m}^{3} / \mathrm{s}$

- static pressure ratio: $\quad \Pi_{A-Z}=1.4$

Vapour-contaminated air was the working medium. The fact that the blower was a prototype limited considerably the range of technologies that could be applied. The welding of steel sheets was assumed as the only applicable manufacturing technology.

If we assume the gas constant of the compressed medium to be $R=302 \mathrm{~J} /(\mathrm{kg} \cdot \mathrm{K}$ ) (the range from $R_{\text {min }}=292.6$ up to $312.0 \mathrm{~J} /(\mathrm{kg} \cdot \mathrm{K})$ was given $)$, it turns out that for the assumed inner isentropic efficiency $\eta_{i}=0.65$ and radial impeller blades, the required circumferential velocity of the impeller wheel will exceed $u_{2}=370 \mathrm{~m} / \mathrm{s}$. For such high circumferential velocity, it is impossible to have a closed (i.e. with a shroud) structure of the impeller wheel. The reason lies in the low strength characteristics of heat-resistant steels. Conversely, highresistant structural steels usually applied in the manufacturing of compressors have too low a yield point and creep resistance at temperatures exceeding $400^{\circ} \mathrm{C}$ as well. This means that it is impossible to build a onestage machine from a technological point of view.

Finally, the following design concept was assumed:

- the compressor unit would consist of four twin blowers, operating serially,

- each blower would be built with a high-speed flangetype engine (with external cooling), driven by an inverter.

A scheme of a single blower in the above-discussed unit is presented in Fig. 6 .



Fig. 6. Longitudinal section of a single blower.

As mentioned above, the most important element in this design is a high-speed electrical motor with external cooling 1 . The main body of the blower is suspended on flange projection 2 of the electric motor. The body is mounted with four screws. The first element in the main body is a water chamber, which serves to insulate the electric motor. Water chamber 3 is supplied from the top with water, which flows out at the bottom. Both the pipelines - inlet and outlet - are provided with throttling valves. Impeller wheel 4 (shown as an example) is directly mounted on the motor shaft and fixed axially with a screw. The impeller hub is cooled with air supplied from outer installation 7. Hub cooling will increase the material strength and will eliminate the risk that the impeller wheel will loosen radially (which will be followed by an increase in the vibration level).

Due to material strength issues, it was assumed that the impeller wheel would have blades with an outlet angle $\beta_{2}{ }^{*}=90^{\circ} \mathrm{C}$ (outlet radial blades). As the stream angle in the absolute frame of reference is also negligible, vaned diffuser 5 has to be used. Welded diffuser vanes contribute to the strength of the machine 
as they close the collective volute by force. The main body of the blower is heat insulated with a mineral wool matt.

It was assumed that the impeller wheel would be made of 316L steel, which at its operating temperature has a Young modulus $E=160 \mathrm{GPa}$ and a yield point of $100 \mathrm{MPa}$. The scarcity of this material, however, and its exceedingly low mechanical properties and difficulties with welding technology compelled the designers to use Avesta $253 \mathrm{MA}$ steel. Unfortunately, in this case, the design of the whole structure and the impeller wheel had to be altered, as shown in Fig. 7.

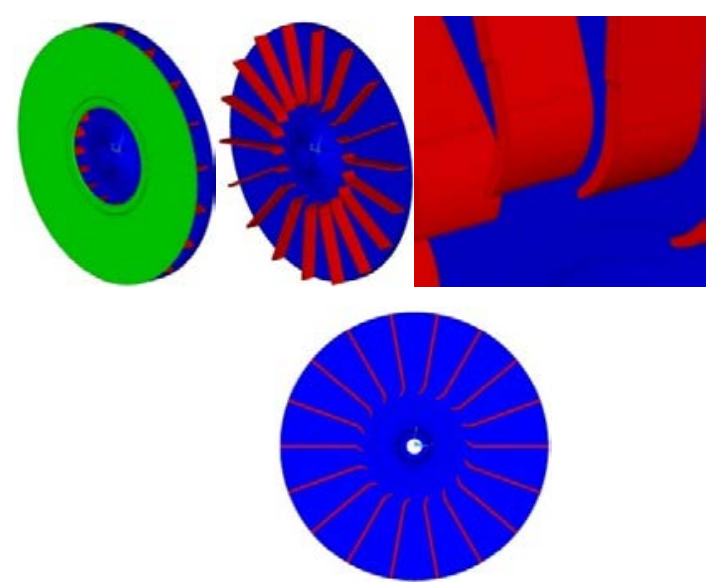

Fig. 7. 3D model of the impeller wheel in its final version.

Strength calculations were carried out for that model and their selected results are depicted in Fig. 8.

a)

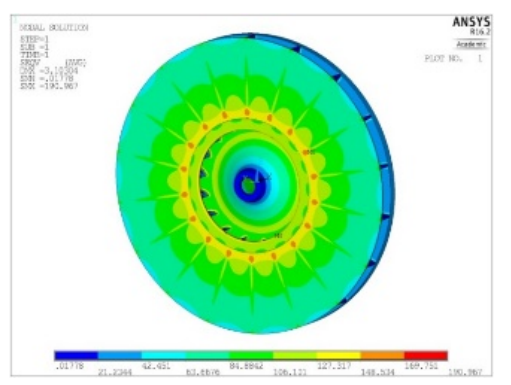

b)

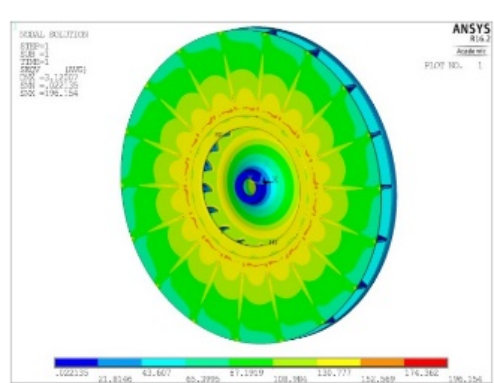

Fig. 8. Distribution of reduced stresses in the impeller shroud, inner view:
a) $n=4500 \mathrm{rpm}$,
$\left(\sigma_{\text {red } \max }=151 \mathrm{MPa}\right)$
b) $n=5000 \mathrm{rpm}$.
$\left(\sigma_{\text {red } \max }=155 \mathrm{MPa}\right)$

The stress level obtained in the calculations does not exceed the allowable value.

The blower thus designed was launched in a Polish paper-making company, in the context of the GEKON programme [9].

\section{Summary}

On the basis of the two different designs of compressors and blowers presented in this paper, several remarks on the optimisation methods of such machines can be formulated. Kleinhenz [2] presented the requirements referring to the characteristics of machines that compress water vapour. Following an analysis of the abovementioned designs, it is possible to state that these machine units represent entirely different technological advancements. "Low-temperature" compressors are cutting-edge devices, whereas a set of "hightemperature" blowers falls far behind as far as the technological level is concerned.

Both compressors, however, although different, accomplish their task. It should also be emphasised that they are very cheap solutions in comparison to similar machines available on the European market.

\section{References}

1. M.A. Darwish, The heat recovery thermal vapour compression desalting system. A comparison with other thermal desalination systems (Applied Thermal Engineering, Volume 16, Issue 6, pp. 523537, 1996)

2. K. Kleinhenz, Forderungen on Bruedenverdichter bei Wasserdampf und bei anderen Medien (VDI Berichte, $\mathrm{Nr} 442,45$ )

3. W. Kryłłowicz, Teoria $i$ praktyka modernizacji spręzarek promieniowych (Theory and praxis of centrifugal compressors modernisation) (Monograph, Technical University of Lodz, 2013)

4. M. Lucas, B. Tabourier, The Mechanical vapour compression process applied to sea water desalination a 1500 ton/day unit installed in the nuclearpower plant of Flamanville, (Desalination, Volume 52, Issue 2, pp. 123-133, 1985)

5. K.H. Luedke, Process centrifugal compressors (Springer - Verlag, 2004)

6. J.A. Winchester, C. Marsh, Dynamics and Control of Falling Film Evaporators with Mechanical Vapour Recompression Engineering Research and Design (Volume 77, Issue 5, pp. 357-371, July 1999)

7. R. Wimmerstedt, Mechanical Vapour Recompression applied to Separation Processes (J. Separ. Proc. Technol. 6, 1985)

8. Mechanische Brueden - Compression (VDI-GET, Braunschweig, 1987)

9. GEKON programme 2/05/268278/22/2016, Increasing wastepaper recycling, decreasing energy consumption and improving drying process efficiency in the papermaking machine through an application of micro-nozzle systems) (in Polish, final report of the project, 2016) 